\title{
Making sense of policy choices: understanding the roles of value predispositions, mass media, and cognitive processing in public attitudes toward nanotechnology
}

\author{
Shirley S. Ho • Dietram A. Scheufele • \\ Elizabeth A. Corley
}

Received: 29 November 2009/ Accepted: 16 July 2010/Published online: 1 August 2010

(C) Springer Science+Business Media B.V. 2010

\begin{abstract}
Using a nationally representative telephone survey of 1,015 adults in the United States, this study examines how value predispositions, communication variables, and perceptions of risks and benefits are associated with public support for federal funding of nanotechnology. Our findings show that highly religious individuals were less supportive of funding of nanotech than less religious individuals, whereas individuals who held a high deference for scientific authority were more supportive of funding of the emerging technology than those low in deference. Mass media use and elaborative processing of scientific news were positively associated with public support for funding, whereas factual scientific knowl-
\end{abstract}

S. S. Ho $(\square)$

Wee Kim Wee School of Communication and Information, Nanyang Technological University, 31 Nanyang Link, Singapore 637718, Singapore e-mail: tsyho@ntu.edu.sg

\section{A. Scheufele}

Department of Life Sciences Communication, University of Wisconsin-Madison, 309 Hiram Smith Hall, 1545 Observatory Drive, Madison, WI 53706-1215, USA e-mail: scheufele@wisc.edu

\section{E. A. Corley}

School of Public Affairs, Arizona State University,

411 N. Central Avenue, Suite 450, Phoenix,

AZ 85004-0687, USA

e-mail: elizabeth.corley@asu.edu edge had no significant association with policy choices. The findings suggest that thinking about and reflecting upon scientific news promote better understanding of the scientific world and may provide a more sophisticated cognitive structure for the public to form opinions about nanotech than factual scientific knowledge. Finally, heuristic cues including trust in scientists and perceived risks and benefits of nanotech were found to be associated with public support for nanotech funding. We conclude with policy implications that will be useful for policymakers and science communication practitioners.

Keywords Mass media - Elaborative processing · Interpersonal discussion · Risk · Nanotechnology · Societal implications · ELSI

\section{Introduction}

Nanotechnology is projected by the federal government to be the defining technology of the twenty-first century, with the potential to drive our next industrial revolution (National Science Technology Council 2000). According to the 2006 State of the Union Speech by President George W. Bush, nanotech is among the emerging technologies for which funding will be doubled over the next ten years in the United States. With wide applications cutting across important sectors such as medicine and healthcare, environment, 
and national defense, nanotech promises to overcome many of the challenges that the world faces today (National Science Technology Council 2000). In 2007 alone, US\$147 billion worth of nanotech-enabled products were produced in the market, and the annual global revenue of nanotech-based products is expected to reach US\$3.1 trillion by 2015 (Lux Research 2008). Despite this, there are fears that the novel technology could lead to various health and environmental problems, and other negative social, moral, and ethical consequences (Bainbridge 2003; Sententia 2004; PCAST 2005).

Currently, the American public is unaware of the potential risks and benefits of this emerging technology (Scheufele and Lewenstein 2005). Public opinion about nanotech is likely to have a bearing on future funding-related policies (Roco and Bainbridge 2003). Although the U.S. is currently leading the "nano race" in terms of public and private funding (European Commission 2005), this technological supremacy may be threatened if public attitudes toward nanotech were to turn negative. For example, if funding and infrastructure support for nano-scientists in the U.S. were insufficient, then they may choose to relocate their research base to other countries with more attractive funding opportunities. Insuring constant funding initiatives for nanotech will enable the U.S. to remain competitive in the international arena and to sustain a positive climate for science and technology in the country. Since the public is primarily unfamiliar with nanotech at this early stage, examining the mechanism behind how the public forms attitudes toward support for federal funding of nanotech is pertinent.

Thus far, there are two lines of assertions that explain how the public forms attitudes toward nanotech. First, the deficit models of attitude formation assert that public support for nanotech will likely grow as awareness or knowledge of it expands. Comparing various public opinion studies of nanotech, Satterfield et al. (2009) have demonstrated that familiarity with nanotech is correlated with positive attitudes toward it, in which members of the public who claim to know a lot about nanotech were substantially more likely to believe its benefits outweigh its risks. Conversely, the predisposition argument asserts that personal values and heuristics could play a bigger part in shaping public attitudes toward nanotech. For example, individuals who hold a pro-science and technology orientation are predisposed to seek out scientific information from the mass media, to discuss science with others, which in turn, produces positive attitudes toward nanotech (Vandermoere et al. 2010).

Since these arguments are far from conclusive, this study aims to use a holistic approach to examine how both cognitive and heuristic factors can potentially shape public level of support for federal funding of nanotech. Previous studies have shown that public attitudes toward emerging technologies are associated with value predispositions such as religious beliefs and deference to scientific authority, and other heuristic cues such as risk and benefit perceptions (e.g., Ho et al. 2008; Nisbet et al. 2002; Priest 2001; Priest et al. 2003; Scheufele et al. 2009). Scholars have also shown that the public often rely on positive frames and/or information in the media to form favorable attitudes toward nanotech (e.g., Brossard et al. 2009; Lee et al. 2005; Scheufele and Lewenstein 2005).

In addition, individuals' use of cognitive processing strategies to reflect upon and absorb the scientific information that they gathered from the mass media can also be associated with their acceptance of the new technology. Scientific knowledge has been demonstrated to have a small association with public acceptance of emerging technologies (e.g., Miller et al. 1997; Miller and Kimmel 2001). We will, therefore, examine how these factors are associated with public support for funding of nanotech in this study.

\section{Value predispositions}

Religious guidance is a likely heuristic cue which the public will depend on to form judgments about nanotechnology. Recent research has shown that religious guidance is one of the major factors associated with public resistance to emerging science and technologies (Brossard et al. 2009; Gaskell et al. 2004; Ho et al. 2008; Nisbet 2005). This is hardly surprising given the historical intransigence and normative inconsistencies between religion and science (Brooke 1998; Miller et al. 1997). One explanation for this tension has to do with the perception that science tampers with nature or is akin to playing God, putting it at odds with religious beliefs (Sjoberg 2004; Sjoberg and Winroth 1986).

Nanotech is not spared from the potential friction between religion and science. The U.S. Food and Drug 
Administration officially defined nanotech as part of the Nano-Bio-Info-Cogno (NBIC) technologies that highlight the unity of nature at the nanoscale, and the intelligible processes of evolution that have constructed life and intelligence, from the nanoscale, without divine intervention (Bainbridge 2003; Sententia 2004). Bainbridge (2003) argued that this allinclusive approach to nanotech may go against people's religious beliefs and reduce their support for the emerging technology.

Brossard et al. (2009) found a negative relationship between the strength of religious beliefs and support for funding of nanotech among the U.S. public. They concluded that people use religiosity as an attitudinal filter when it comes to forming opinions about the new technology. Religious people may lump nanotech, biotech, and stem cell research together and perceive them as means to enhance human qualities. In short, some people may believe that researchers are "playing God" when they create materials that do not occur in nature, especially where nanotech and biotech intertwine. Based on these considerations, we, therefore, hypothesize that religious beliefs will be negatively associated with public support for federal funding of nanotech (Hypothesis 1).

Deference to scientific authority is another value predisposition that can be associated with attitudes toward science and technology (Brossard and Nisbet 2007; Ho et al. 2008). Deference to scientific authority is defined as "a long-term socialized trait that guides citizens' responses to a range of technical controversies" (Brossard and Nisbet 2007, p. 10). Studies have demonstrated that the more individuals defer to scientific authority, the more likely they were to hold positive views on controversial scientific issues (e.g., Brossard and Nisbet 2007; Ho et al. 2008). The American educational system has instilled a strong sense of respect for scientists and scientific institutions among the citizens, and this has fostered a culture of deference to scientific authority in the U.S. These have been reflected in education that involved teaching people to view scientific research as solitary activities that are kept away from external social and political pressures (Bimber and Guston 1995), and to perceive science as a pure and unbiased pursuit that increases our knowledge about the world (Irwin 2001). Hence, we posit that deference for scientific authority will be positively associated with public support for federal funding of nanotech (Hypothesis 2).

\section{Mass media}

The mass media is the main source of information about science and technology for the majority of the public (Pew Internet and American Life Project 2006), and media coverage has been shown to play an important role in shaping public attitudes toward science and technology (Ho et al. 2007, 2008; Nisbet et al. 2003; Nisbet and Lewenstein 2002). In a content analysis of the New York Times from 2000 to 2003, Gaskell et al. (2004) found an overwhelming coverage of benefits over risks for nanotech, and concluded that "media coverage is more slanted towards a supportive culture of science and technology in the U.S." (p. 496)

Likewise, by examining nanotech coverage in major U.S. and non-U.S. newspapers published from 1988 through 2004, Stephens (2005) found that the proportion of articles in which benefits outweigh risks (vs. risks outweigh benefits) is three to one. Friedman and Egolf (2005) shown that even when health and environmental risks were covered in the U.S. newspapers, most of the articles published were balanced and described risks with both positive and negative information. The researchers concluded that news coverage in the U.S. would positively influence public opinion about nanotech (see also, Scheufele and Lewenstein 2005).

Besides this, some scholars have argued that the tone of media coverage of nanotech can serve as a simple decision rule in influencing the risks and benefits considerations among the public (Nisbet and Scheufele 2007; Scheufele and Lewenstein 2005). This is manifested in the form of media frames in which audiences use these heuristic cues as shortcuts for processing new information in a short time (Cacciatore et al. forthcoming; Scheufele 1999). Studies have shown that framing of nanotech has an effect on how audiences perceived risks and benefits of the technology (e.g., Cacciatore et al. forthcoming; Cobb 2005; Schutz and Wiedemann 2008).

In essence, the mass media has a dual function. On one hand, the media are information providers that offer a source of informal learning about emerging science for most Americans. On the other hand, media frames such as the positive tone of coverage about nanotech offer audience the heuristic cues to make quick decisions about the technology (Scheufele and Lewenstein 2005). Given the overall positive content and valence of the news media on nanotech 
over the past few years, we postulate that mass media use will be positively associated with public support for federal funding of nanotech (Hypothesis 3).

\section{Elaborative processing and interpersonal discussion}

Going beyond mass media use, individuals' cognitive processing in the form of reflective integration (i.e., news elaboration and interpersonal discussion about scientific issues) can be associated with public attitude toward nanotech. Cognitive information-processing strategies are defined (Kosicki and McLeod 1990) as "tactics that individuals use to try to cope with the amount and kind of mass media information that they encounter in their everyday lives" (p. 73). Most people are cognitive misers who tend to engage in reflective integration to sift out media messages that are useful to them. Specifically, reflective integration consists of thinking about a specific issue covered in the mass media (i.e., news elaboration) and talking about it with others by connecting it with pre-existing knowledge (i.e., interpersonal discussion) (Eveland 2001, 2002; Eveland and Thomson 2006).

Elaboration is a behavioral style that people use to associate new ideas and information with what is already known, look for similarities with past experiences, and find ways to apply the information (Eveland 2002). Any new information incorporated into a pre-existing knowledge structure through the process of news elaboration will promote a deeper understanding of the scientific world. Likewise, interpersonal discussion (Kosicki and McLeod 1990; Scheufele 2001, 2002) involves talking to other people about mass-mediated issues, discussing the pros and cons, and weighing alternatives to reach a conclusion. Discussions with family, friends, neighbors, and coworkers are likely to reinforce mass media effects (Johnson 1993). Since the media has on the most part portrayed nanotech and science in general favorably, interpersonal discussion about science and nanotech should reinforce this perspective.

Reflective integration can promote a deeper understanding of the scientific world and provides a stronger cognitive base and sophisticated knowledge structure for opinion formation about scientific issues than simple factual, textbook-style scientific knowledge. By sophisticated knowledge, we are referring to the ability of individuals to associate, integrate, and relate various news issues or topics, which will also include the knowledge of how concepts within a specific domain are interrelated. We, therefore, hypothesize that elaborative processing will be positively associated with public support for federal funding of nanotech (Hypothesis 4), and that science discussion will be positively associated with public support for funding (Hypothesis 5).

\section{Factual scientific knowledge}

Scientists and policymakers have assumed that greater scientific literacy enables individuals to sort through the misinformation and extraordinary claims that emerge during scientific disagreements (Bodmer 1985). Scholars also assume that a highly knowledgeable public would be more supportive of scientific research (Miller 1998, 2004). Scientific knowledge has been shown to have direct positive relations with public perceptions of scientific issues (Brossard and Nisbet 2007; Nisbet et al. 2002; Sturgis et al. 2005), and to have contingent associations with public attitudes toward science and technology (e.g., Brossard et al. 2009; Ho et al. 2008; Sturgis and Allum 2004). However, some studies have shown that factual scientific knowledge had little or no relationship with public acceptance of new technologies (e.g., Allum et al. 2008; Priest 2001).We, therefore, pose the following research question: how will scientific knowledge be associated with public support for federal funding of nanotech? (Research Question 1).

\section{Trust in scientists}

Trust refers to citizens' willingness to rely on the endorsements of experts, such as scientists and regulators, as well as institutions such as the federal government, to manage risks associated with emerging technologies (Earle and Cvetkovich 1995; Giddens 1991; Luhmann 1979; Sztompka 1999). Giddens (1991) pointed out that trust in a variety of abstract systems is a necessary part of everyday life, and the characteristics of abstract systems imply constant interaction with "absent others"-people we have never met but whose actions directly affect our lives. Irwin and Wynne (1996) demonstrated that people 
were much more concerned with whom to trust than with the scientific aspects of an issue itself. Trust is a state-like disposition which acts as an uncertainty reduction mechanism, driving down citizens' concerns over the unforeseen risks and costs of emerging science and technologies (Freudenburg 1992, 1993; Slovic 1999), thereby enabling citizens to form judgments about emerging technology without understanding the risks involved.

Numerous studies found trust in relevant actors to be positively associated with support for emerging science such as biotech (Brossard and Nisbet 2007; Brossard and Shanahan 2003; Priest 2001; Priest et al. 2003; Sinclair and Irani 2005), gene technology (Siegrist 2000), stem cell research (Ho et al. 2008), and nanotech (Ho et al. forthcoming; Lee et al. 2005). Trust as a tool in decision making is efficient when individuals have limited knowledge and personal experience, and when they have little chance to anticipate the future consequences of a particular technology (Olofsson et al. 2006). This is highly applicable to the emerging nanotech field with which most people are unfamiliar with. Therefore, it is likely that trust in scientists will be positively associated with public support for funding of nanotech (Hypothesis 6).

\section{Perceptions of risks and benefits}

Public perceptions of risks and benefits can be related to their decision making about funding for nanotech. Coming from the psychometric approach, Slovic (1987) defines risk perceptions as "the judgments people make when they are asked to characterize and evaluate hazardous activities and technologies" (p. 280). Researchers have shown that the public tends to perceive hazards as risky if they are not within their control (Starr 1969), seem "dreadful" and "novel" (Fischhoff et al. 1978), and interfere with nature (Sjoberg 2002). The more individuals perceive a hazard or a technology as risky, the less likely they are to accept it.

Numerous studies have found that perceived risks and benefits are associated with levels of acceptance of technology (Frewer et al. 1998; Siegrist 2000; Siegrist et al. 2000; Sjoberg 2002, 2004). For example, Siegrist (2000) demonstrated that while perceived benefits were positively associated with acceptance of gene technology, perceived risks were negatively associated with support for the technology. Sjoberg (2004) opined that outright rejection of an emerging technology is often a function of perceived high risks in the technology per se. Given the fact that the "real" risks are not apparent for nanotech at the current stage of its development, and media coverage of this emerging technology is overwhelmingly positive, simply examining risks perception without consideration for the perceived benefits of the technology would preclude us from gaining a full understanding of public opinion. Hence, it is worthwhile to examine the relationship between perceptions of risks and benefits and public support for funding of nanotech. We hypothesize the following: perceived risks will be negatively associated with public support for federal funding of nanotech (Hypothesis 7), and perceived benefits will be positively associated with public support for federal funding of nanotech (Hypothesis 8).

Numerous studies have shown that age, gender, and socioeconomic status (SES) were significantly related to public acceptance of nanotech and other emerging technologies (e.g., Bodmer 1985; Brossard and Nisbet 2007; Brody 1984; Lee et al. 2005; Ho et al. 2008; Scheufele et al. 2009). These factors will be included as control variables in our analysis.

\section{Methods}

Our data came from a nationally representative random-digit-dial telephone survey of U.S. adult respondents aged 18 years and over $(N=1,015)$. The University of Wisconsin-Madison Survey Center conducted the fieldwork between May and July 2007 with an average length of 21.47 min per interview. The margin of error was approximately $\pm 3 \%$. A significant amount of time and effort were put into call-backs and refusal conversions to minimize systematic non-response. The overall response rate for this survey was $30.6 \%$ (based on AAPOR response rate formula 3 calculation that includes both refusals and unreachable but eligible telephone numbers).

Hierarchical OLS regression analysis was used to investigate the relationships between the independent variables and public support for funding of nanotech. The variables were entered into the regression model based on their assumed order: the control variables (i.e., age, gender, and SES) were entered in the first 
block, followed by value predispositions (i.e., religious beliefs and deference to scientific authority), mass media use, reflective integration (i.e., elaborative processing and science discussion), factual scientific knowledge, and finally, other perceptions (i.e., trust in scientists and risks and benefits perceptions of nanotech). The specific question wording for the variables can be found in Appendix 1 .

Table 1 summarizes the descriptive statistics for all the variables. For the control variables, we included age $(M=46.15, \mathrm{SD}=17.07)$ and gender $(51.4 \%$ females). SES was an average index of formal education (Median $=5.00$, or "some college or technical school," SD = 1.57) and household income (Median $=6.00$, or "household income between $\$ 50,000$ and $\$ 75,000, " \mathrm{SD}=1.92)(r=0.43, p<0.001)$.

Table 1 Descriptive statistics (means and standard deviations) of control, independent, and dependent variables $(N=1,015)$

\begin{tabular}{|c|c|c|}
\hline & $M$ & SD \\
\hline \multicolumn{3}{|l|}{ Control variables } \\
\hline Age & 46.15 & 17.07 \\
\hline Gender & $51.4 \%$ females & - \\
\hline \multicolumn{3}{|l|}{ SES } \\
\hline Education & $\begin{array}{l}5.00 \text { (Median }= \\
\text { "some college } \\
\text { or technical } \\
\text { school") }\end{array}$ & 1.57 \\
\hline Household income & $\begin{array}{l}6.00 \text { (Median }= \\
\text { "household income } \\
\text { between } \$ 50,000 \\
\text { and } \$ 75,000 ")\end{array}$ & 1.92 \\
\hline \multicolumn{3}{|l|}{ Independent variables } \\
\hline Religious beliefs & 6.00 & 3.01 \\
\hline $\begin{array}{l}\text { Deference to } \\
\text { scientific authority }\end{array}$ & 4.30 & 2.02 \\
\hline Mass media use & 4.73 & 2.12 \\
\hline Elaborative processing & 7.15 & 2.11 \\
\hline Science discussion & 4.40 & 2.18 \\
\hline $\begin{array}{l}\text { Factual scientific } \\
\text { knowledge }\end{array}$ & 3.44 & 1.25 \\
\hline Trust in scientists & 6.16 & 2.00 \\
\hline Perceived risks ${ }^{\mathrm{a}}$ & 33.75 & 12.27 \\
\hline Perceived benefits ${ }^{\mathrm{a}}$ & 47.50 & 14.48 \\
\hline \multicolumn{3}{|l|}{ Dependent variable } \\
\hline $\begin{array}{l}\text { Support for federal } \\
\text { funding of nanotech }\end{array}$ & 5.90 & 2.85 \\
\hline
\end{tabular}

${ }^{\text {a }}$ Numeric values reported are additive scores
Religious beliefs were a single-item measure $(M=$ $6.00, \mathrm{SD}=3.01$ ). Deference to scientific authority was an average index of two items $(M=4.30$, $\mathrm{SD}=2.02, r=0.39, p<0.001)$. Mass media use was constructed as an average index of nine items $(M=4.73, \mathrm{SD}=2.12$, Cronbach's alpha $=0.89)$. Elaborative processing was an average index of two items $(M=7.15, \mathrm{SD}=2.11, r=.42, p<0.001)$. Science discussion was an average index of three items $(M=4.40, \mathrm{SD}=2.18$, Cronbach's alpha $=0.90)$. Factual scientific knowledge was an additive index of five dichotomous items ( $M=3.44, \mathrm{SD}=1.25$, KR$20=0.47)$. Trust in scientists was measured using an average index of two items $(M=6.16, \mathrm{SD}=2.00$, $r=0.58, p<0.001)$.

Perceived risks of nanotech were created by constructing an additive index of seven ten-point items $(M=33.75, \mathrm{SD}=12.27$, Cronbach's alpha $=$ 0.82 ). Then, perceived benefits of nanotech were created by constructing an additive index of seven tenpoint items $(M=47.50, \mathrm{SD}=14.48$, Cronbach's alpha $=0.91)$. For the dependent variable, support for federal funding of nanotech was measured using one item on a ten-point scale $(M=5.90, \mathrm{SD}=2.85)$.

\section{Results}

Table 2 shows the hierarchical OLS regression analysis for support for federal funding of nanotech. The results show that all the control and independent variables were significantly correlated with public support for funding of nanotech at the zero-order level, indicating potential multivariate relationships between them.

The first block of final standardized beta coefficients indicates the role of the demographic variables. Age, gender, and SES were initially correlated with support for funding at the zero-order level, but the significant associations were fully explained away by the independent variables that were subsequently entered into the regression model. The demographic block accounted for $6.80 \%$ of the variance in the model.

When it comes to value predispositions, the negative final standardized beta coefficient shows that highly religious individuals were significantly less supportive of nanotech funding than the less religious individuals. Conversely, the positive beta coefficient indicates that individuals who had a high deference 
Table 2 Hierarchical OLS regression analysis for public support for federal funding of nanotechnology

\begin{tabular}{|c|c|c|}
\hline Variables & $\begin{array}{l}\text { Zero-order } \\
\text { correlations }\end{array}$ & $\begin{array}{l}\text { Final } \\
\text { standardized } \\
\text { beta }\end{array}$ \\
\hline \multicolumn{3}{|l|}{ Block 1: demographics } \\
\hline Age & $-0.15^{* * *}$ & -0.05 \\
\hline Gender & $-0.10 * * *$ & -0.01 \\
\hline SES & $0.23 * * *$ & 0.04 \\
\hline Incremental $R^{2}(\%)$ & & $6.80 * * *$ \\
\hline \multicolumn{3}{|l|}{ Block 2: value predispositions } \\
\hline Religious beliefs & $-0.21 * * *$ & $-0.09 * * *$ \\
\hline $\begin{array}{l}\text { Deference to scientific } \\
\text { authority }\end{array}$ & $0.29 * * *$ & $0.12 * * *$ \\
\hline Incremental $R^{2}(\%)$ & & $9.30 * * *$ \\
\hline \multicolumn{3}{|l|}{ Block 3: mass media } \\
\hline Mass media use & $0.33 * * *$ & $0.07 *$ \\
\hline Incremental $R^{2}(\%)$ & & $5.70 * * *$ \\
\hline \multicolumn{3}{|l|}{ Block 4: reflective integration } \\
\hline Elaborative processing & $0.31 * * *$ & $0.06 *$ \\
\hline Science discussion & $0.28 * * *$ & 0.05 \\
\hline Incremental $R^{2}(\%)$ & & $2.80 * * *$ \\
\hline \multicolumn{3}{|l|}{ Block 5: knowledge } \\
\hline Factual scientific knowledge & $0.22 * * *$ & 0.00 \\
\hline Incremental $R^{2}(\%)$ & & 0.00 \\
\hline \multicolumn{3}{|l|}{ Block 6: other perceptions } \\
\hline Trust in scientists & $0.43 * * *$ & $0.13 * * *$ \\
\hline Perceived risks & $0.06 *$ & $-0.10 * *$ \\
\hline Perceived benefits & $0.54 * * *$ & $0.40 * * *$ \\
\hline Incremental $R^{2}(\%)$ & & $14.50 * * *$ \\
\hline Total $R^{2}(\%)$ & & $39.30 * * *$ \\
\hline
\end{tabular}

$* p<0.05, * * p<0.01, * * * p<0.001$

for scientific authority were significantly more supportive of funding of the emerging technology than those low in deference. Hence, both $\mathrm{H} 1$ and $\mathrm{H} 2$ were supported. The value predispositions block explained $9.30 \%$ of the variance in our model.

After controlling for the demographics and value predispositions, our results show that mass media use and elaborative processing were positively associated with public support for funding. However, interpersonal discussion of scientific issues had no significant association with the dependent variable. Therefore, $H 3$ and $H 4$ were supported, but not $H 5$. The science media use and reflective integration blocks accounted for a combined $8.50 \%$ of the variance in public support for funding. With respect to $R Q 1$, our results indicate that factual scientific knowledge had no significant association with policy choices.

Finally, the positive beta coefficients indicate that individuals who had a lot of trust in scientists were more supportive of nanotech funding than those who had a low trust in scientists. Perceptions of risks were negatively, while perceptions of benefits were positively associated with public support for funding of nanotech. This supported $H 6, H 7$, and $H 8$. The final block accounted for $14.50 \%$ of the variance in our dependent variable. In total, the factors explained $39.30 \%$ of the variance in our model.

\section{Discussion}

This study examined the associations of value predispositions, mass media use, reflective integration, factual scientific knowledge, trust in scientists, and risks and benefits perception with public support for federal funding of nanotech. Overall, our findings provide support for the hypothesis that mass media use had a positive association with public support for federal funding of nanotech. Notably, the results support the hypothesis that elaborative processing was positively associated with public attitudes toward nanotech. Heuristics in the form of value predispositions, trust, and risks and benefits perceptions were also shown to have bearing on public support for funding. Taken together, these findings underscore the important roles of cognitive and heuristic cues when it comes to understanding how the public form attitude toward emerging technologies. Using this holistic approach, the findings are useful for designing more effective science communication and public outreach efforts.

Consistent with results from previous studies (e.g., Brossard et al. 2009; Ho et al. 2008; Nisbet 2005), this study showed that religious belief was negatively related to public support for federal funding of the emerging technology. The normative contradictions between science and religion (Brooke 1998; Miller et al. 1997) may be an explanation for the relationships found between religious guidance and acceptance of nanotech. In addition, the fact that religious people may perceive nanotech, biotech, and stem cell research together as means to enhance human qualities, hence tampering with nature by playing God (Sjoberg 2004; Sjoberg and Winroth 1986) may plausibly explain the negative relationship. 
On the other hand, individuals' deference for scientific authority and trust in scientists are two positive factors associated with public acceptance of nanotech, consistent with findings from previous studies (Brossard and Nisbet 2007; Ho et al. 2008; Lee et al. 2005). Again, these findings are not surprising because, as tools in decision making, deference for scientific authority and trust in scientists are efficient when knowledge and personal experience are limited, especially when it comes to nanotech. In addition, the independent effects of deference to scientific authority and trust in scientists on public attitudes toward nanotech suggest that researchers should adopt a fine-grained approach to examine these concepts separately in future studies as they are essentially different entities.

Then, this study shows that the public utilize positive frames derived from the mass media as heuristic cues to make decision about acceptance of the emerging technology, which is congruent to the results of previous studies (Brossard and Nisbet 2007; Lee and Scheufele 2006; Lee et al. 2005; Scheufele and Lewenstein 2005) and consistent with framing effects of the media (Kahneman and Tversky 1979; Scheufele 1999). This could plausibly be explained by the fact that media outlets are the major gateway to nanotech for most Americans (Castellini et al. 2007), and that the tone of media coverage of nanotech has been overwhelmingly optimistic in the past few years (Bainbridge 2002; Gaskell et al. 2004).

Besides this, elaborative processing plays an important role in shaping public support for federal funding of the new technology. This could be explained by the fact that people who actively process and synthesize information from the mass media build a larger knowledge structure about science generally, and nanotech specifically, in their memory. This new scientific information could be easily accessed for people to formulate judgments about nanotech acceptance. Nanotech has been covered in overwhelmingly positive light in the mass media, and it is, therefore, not surprising that these positive data become part of the audience memory when audiences reflect and integrate the materials that they attended to in the news.

Contrary to our expectation, scientific discussion was not found to be significantly associated with public support for federal funding of nanotech. Interpersonal discussion with others about scientific issues was initially correlated with support for funding at the zero-order level, but the relationship was explained away by other variables (e.g., perceived risks and benefits) that were subsequently entered into the regression model. Another plausible explanation may be that people may not be talking about nanotech per se in their discussions about scientific issues, and therefore the association with attitude toward the emerging technology is not strong.

Consistent with results of previous studies (e.g., Brossard et al. 2009), individuals who perceived greater risks of nanotech were less supportive of nanotech funding, while those who perceived greater benefits were more supportive of funding for nanotech. This suggests that the public rely on risks and benefits perceptions as heuristic cues to form judgment about nanotech.

This study has important policy implications that will be useful for policymakers and science communication practitioners. Given that there are various groups that have different opinions about nanotech (such as the highly religious public), science communication practitioners should adopt the target segmentation strategy, in which communication messages are tailored to fit with publics from different social backgrounds for maximum effect. For example, to reach out to the religious public, scientific institutions should strengthen partnerships with religious institutions by arranging scientists to speak on topics related to nanotech and inviting religious leaders to address scientists on issues of concern.

At the same time, policymakers and the relevant scientific institutions should find ways to promote and instill trust in scientists and deference to scientific authority among the public (e.g., arranging eminent scientists to conduct seminars for high-school students) so as to counter the opposing force that religious guidance could potentially play in shaping opinion about nanotech. In addition, trust in nanoscientists both in academia and in industry is crucial to sustain public support for nanotech. Therefore, government regulatory bodies should insure that the necessary guidelines are in place (e.g., guidelines to manage toxicity related to nanotech and health standards for creating commercial products) so that public confidence and trust is maintained.

Given the findings that the mass media plays a key role in shaping public perceptions of nanotech by providing heuristic cues and/or information, policymakers and scientists should learn to focus on framing 
their messages in ways that connect with diverse audience. For example, when scientists are speaking to a group of businessmen, they should emphasize the economic relevance of science by pointing out that expanded government funding would make the U.S. more economically competitive. It is important for public officials, scientists, and science communicators to pay attention to new developments in media coverage of nanotech to monitor public opinion movements, especially when the issue of nanotech enters into different stages of the issue-attention cycle. The mass media could also be a point of intervention for public officials as they could provide accurate and up-to-date information about nanotech to the public so as to sustain positive public opinion. For example, public officials could use the mass media as an avenue, such as running campaigns and sponsoring science programs on PBS channels, to offer accurate and upto-date information about nanotech to the public.

There are several limitations in this study that could be overcome in future research. First, the crosssectional data used in our study limit the extent to which we can lay claims about the causal direction of the relationships in the regression model. For example, some researchers have conducted studies with methods specifically geared to determining whether information exposure has a positive effect on nanotech (Kahan et al. 2008; Pidgeon et al. 2009). These studies find evidence suggesting that information exposure does not have a uniform positive effect on nanotech views, and might even have a negative effect on individuals who are predisposed to be concerned about environmental risks generally. Nonetheless, our survey serves to sharpen, but does not help to resolve this issue. Future studies could establish time order using panel data or lab experiments to make more rigorous causal inferences. Second, some concepts were operationalized with single-item measures in our study, which meant that we could not control unreliability in some of our measures. However, if we had been able to use multi-item measures, then we would have been likely to find stronger associations for the relationships in our regression model.

Despite this, the findings of this study also inform future research agendas. First, it may be worthwhile for future studies to examine the associations of mass media and reflective integration with other science and technologies that are at different stages of the issue attention cycle, so as to insure that the significant results found in this study are not unique to nanotech. For example, it may be worthwhile to examine public acceptance of embryonic stem cell research and biotech in which the risk aspects had been made salient in the mass media. Second, future studies may also examine reflective integration along with other cognitive information processes such as selective scanning to provide a more complete understanding of how the public form perception about emerging technologies. Finally, future research may move beyond support for funding of nanotech to examine factors that motivate public to actively participate in issues related to nanotech specifically, and science more generally.

Acknowledgments This work was supported by the National Science Foundation [grant number SES-0531194]. Any opinions, findings, and conclusions or recommendations expressed in this material are those of the authors and do not necessarily reflect the views of the NSF.

\section{Appendix 1}

\section{Religious beliefs}

(a) "How much guidance does religion provide in your everyday life?"

$(1=$ "no guidance at all," $10=$ "a great deal of guidance")

Deference to scientific authority

(a) "Scientists know best what is good for the public."

(b) "Scientists should do what they think is best, even if they have to persuade people that it is right."

$(1=$ "do not agree at all," $10=$ "agree very much;" $r=0.39, p<0.001$ )

\section{Mass media use}

Now I would like to ask you about how much attention you pay to news. On a scale from 1 to 10 , where 1 means little attention and 10 means very close attention, please tell me how much attention you pay to the following kinds of stories when you read the newspaper. 
(a) "Stories related to science and technology"

(b) "Stories about scientific studies in new areas of research such as nanotechnology"

(c) "Stories about the social or ethical implications of emerging technologies"

On a scale from 1 to 10 , where 1 means little attention and 10 means very close attention, please tell me how much attention you pay to the following types of content on television.

(a) "Science and technology"

(b) "Specific scientific developments, such as nanotechnology"

(c) "Information about the social or ethical implications of emerging technologies"

Using a scale from 1 to 10 , where 1 means little attention and 10 means very close attention, when you go online to learn about things, how much attention do you pay to the following types of news and information on the Internet?
(a) "Content related to science and technology"
(b) "Content related to specific scientific develop- ments, such as nanotechnology"
(c) "Content related to the social or ethical impli- cations of emerging technologies"

$($ Cronbach's alpha $=0.89)$

Elaborative processing

(a) "After I encounter news about a scientific development, I am likely to stop and think about it"

(b) "If I need to act on science information, the more viewpoints the media give me the better"

$(1=$ "do not agree at all," $10=$ "agree very much;" $r=0.42, p<0.001$ )

Science discussion

Now I would like to ask you how much you talk about news with other people. Using a scale from 1 to 10 , where 1 means never and 10 means all the time, please tell me how often you talk with family, friends, or co-workers about:

(a) "Stories related to science and technology"

(b) "Stories about scientific studies in new areas of research such as nanotechnology" (c) "Stories about the social or ethical implications of emerging technologies"

$(1=$ "never," $10=$ "all the time;" Cronbach's alpha $=0.90)$

Factual scientific knowledge

(a) "Lasers work by focusing sound waves"

(b) "Antibiotics kill viruses as well as bacteria"

(c) "Electrons are smaller than atoms"

(d) "Ordinary tomatoes do not contain genes, while genetically modified tomatoes do"

(e) "More than half of human genes are identical to those of a chimpanzee"

$(\mathrm{KR}-20=0.47)$

Trust in scientists

Now I would like to ask you which of the following sources of information, if any, you trust to tell you the truth about the risks and benefits of nanotechnology. On a scale from 1 to 10 where 1 means you do not trust their information at all and 10 means you trust their information very much, how much do you trust...

(a) "University scientists doing research in nanotechnology"

(b) "Scientists working for the nanotech industry"

$(1=$ "do not trust their information at all," $10=$ "trust their information very much;" $r=0.58, p<$ 0.001 )

Risk perceptions of nanotechnology

(a) "Nanotech may lead to the loss of personal privacy because of tiny new surveillance devices"

(b) "Nanotech may lead to an arms race between the U.S. and other countries"

(c) "Nanotech may lead to new human health problems"

(d) "Nanotech may be used by terrorists against the U.S."

(e) "Because of nanotech we may lose more U.S. jobs"

(f) "Nanotech may lead to the uncontrollable spread of very tiny self-replicating robots" 
(g) "Nanotech may lead to more pollution and environmental contamination"

$(1=$ "do not agree at all," $10=$ "agree very much;" Cronbach's alpha $=0.82$ )

\section{Benefit perceptions of nanotechnology}

(a) "Nanotech may lead to new and better ways to treat and detect human diseases"

(b) "Nanotech may lead to new and better ways to clean up the environment"

(c) "Nanotech may give scientists the ability to improve human physical and mental abilities"

(d) "Nanotech may help us develop increased national security and defensive capabilities"

(e) "Nanotech may lead to technologies that will help solve our energy problems"

(f) "Nanotech may revolutionize the computer industry"

(g) "Nanotech may lead to a new economic boom"

$(1=$ "do not agree at all," $10=$ "agree very much;" Cronbach's alpha $=0.91$ )

Support for federal funding of nanotechnology

(a) "Overall, I support federal funding of nanotechnology"

$(1=$ "do not agree at all," $10=$ "agree very much")

\section{References}

Allum N, Sturgis P, Tabourazi D, Brunton-Smith I (2008) Science knowledge and attitudes across cultures: a metaanalysis. Public Underst Sci 17(1):35-54

Bainbridge WS (2002) Public attitudes toward nanotechnology. J Nanopart Res 4:561-570

Bainbridge WS (2003) Religious opposition to cloning. J Evol Technol 13. http://www.jetpress.org/volume13/bainbridge. html. Accessed 30 Aug 2008

Bimber B, Guston D (1995) Politics by the same means: government and science in the United States. In: Jasanoff $\mathrm{S}$ et al (eds) The handbook of science and technology studies. Sage Publications, Thousands Oaks, pp 554-571

Bodmer W (1985) The public understanding of science. Royal Society, London

Brody CJ (1984) Differences by sex in support for nuclear power. Soc Forces 63:209-228

Brooke J (1998) Science and religion: lessons from history? Science 282(5396):1985-1986
Brossard D, Nisbet MC (2007) Deference to scientific authority among a low information public: understanding U.S. opinion on agricultural biotechnology. Int J Public Opin Res 19(1):24-52

Brossard D, Shanahan J (2003) Do citizens want to have their say? Media, agricultural biotechnology, and authoritarian views of democratic processes in science. Mass Commun Soc 3:291-312

Brossard D, Scheufele DA, Kim E, Lewenstein BV (2009) Religiosity as a perceptual filter: examining processes of opinion formation about nanotechnology. Public Underst Sci 18(5):546-568

Cacciatore MA, Scheufele DA, Corley EA (forthcoming) From enabling technology to applications: The evolution of risk perceptions about nanotechnology. Public Understanding of Science. doi:10.1177/0963662509347815

Castellini OM, Walejko GK, Holladay CE, Theim TJ, Zenner GM, Crone WC (2007) Nanotechnology and the public: effectively communicating nanoscale science and engineering concepts. J Nanopart Res 9:183-189

Cobb MD (2005) Framing effects on public opinion about nanotechnology. Sci Commun 27(2):221-239

Earle TC, Cvetkovich GT (1995) Social Trust: toward a cosmopolitan society. Praeger, London

European Commission (2005) Some figures about nanotechnology R\&D in Europe and beyond. http://cordis.europa. eu.int/nanotechnology. Accessed 20 Aug 2008

Eveland WP (2001) The cognitive mediation model of learning from the news: evidence from non-election, off-year election, and presidential election contexts. Commun Res 28:571-601

Eveland WP (2002) News information processing as mediator of the relationship between motivations and political knowledge. Journal Mass Commun Q 79(1):26-40

Eveland WP, Thomson T (2006) Is it talking, thinking, or both? A lagged dependent variable model of discussion effects on political knowledge. J Commun 56(3):523-542

Fischhoff B, Slovic P, Lichtenstein S, Read S, Combs B (1978) How safe is sage enough? A psychometric study of attitudes toward technological risks and benefits. Policy Sci 9:127-152

Freudenburg W (1992) Heurisics, biases, and the not-so-general publics: expertise and error in the assessment of risks. In: Krimsky S, Golding D (eds) Social theories of risk. Praeger, Westport, pp 229-250

Freudenburg W (1993) Risk and recreancy: Weber, the division of labor, and rationality of risk perceptions. Soc Forces 71:900-932

Frewer LJ, Howard C, Shepherd R (1998) Understanding attitudes to technology. J Risk Res 1:221-235

Friedman SM, Egolf BP (2005) Nanotechnology: risks and the media. IEEE Technol Soc 24:5-11

Gaskell G, Eyck TT, Jackson J, Veltri G (2004) Public attitudes to nanotechnology in Europe and the United States. Nat Mater 3:496

Giddens A (1991) Modernity and self-identity. Polity Press, Cambridge

Ho SS, Brossard D, Scheufele DA (2007) The polls-trends: public reactions to global health threats and infectious diseases. Public Opin Q 71(4):671-692 
Ho SS, Brossard D, Scheufele DA (2008) Effects of value predispositions, mass media use, and knowledge on public attitudes toward embryonic stem cell research. Int J Public Opin Res 20(2):171-192

Ho SS, Scheufele DA, Corley EA (forthcoming) Value predispositions, mass media, and attitudes toward nanotechnology: the interplay of public and experts. Sci Commun

Irwin A (2001) Constructing the scientific citizen: science and democracy in the biosciences. Public Underst Sci 10(1):1-18

Irwin A, Wynne B (eds) (1996) Misunderstanding Science? The public reconstruction of science and technology. Cambridge University Press, Cambridge

Johnson BB (1993) Advancing understanding of knowledge's role in lay risk perception. Risk Issues Health Saf 4:189-212

Kahan DM, Braman D, Slovic P, Gastil J, Cohen G (2008) Cultural cognition of the risks and benefits of nanotechnology. Nat Nanotechnol 4:87-90

Kahneman D, Tversky A (1979) Prospect theory: an analysis of decision under risk. Econometrica 47(2):263-291

Kosicki GM, McLeod JM (1990) Learning from political news: effects of media images and information-processing strategies. In: Kraus S (ed) Mass communication and political information processing. Erlbaum, Hillsdale, pp 69-83

Lee C, Scheufele DA (2006) The influence of knowledge and deference toward scientific authority: a media effects model for public attitudes toward nanotechnology. Journal Mass Commun Q 83(4):819-834

Lee C, Scheufele DA, Lewenstein BV (2005) Public attitudes toward emerging technologies: examining the interactive effects of cognitions and affect on public attitudes toward nanotechnology. Sci Commun 27(2):240-267

Luhmann N (1979) Trust and power. Chichester, Wiley

Lux Research (2008) Overhyped technology starts to reach potential: nanotech to impact $\$ 3.1$ trillion in manufactured goods in 2015. http://www.luxresearchinc.com/press/RELEASE_ Nano-SMR_7_22_08.pdf. Accessed 20 Aug 2008

Miller JD (1998) The measurement of civic scientific literacy. Public Underst Sci 7(3):203-223

Miller JD (2004) Public understanding of, and attitudes toward, scientific research: what we know and what we need to know. Public Underst Sci 13(3):273-294

Miller JD, Kimmel L (2001) Biomedical communications: purposes, audiences, and strategies. Wiley, New York

Miller JD, Pardo R, Niwa F (1997) Public perceptions of science and technology: a comparative study of the European Union, the United States, Japan, and Canada. BBV Foundation, Madrid

National Science Technology Council (2000) National nanotechnology initiative: leading to the next industrial revolution. A report by the Interagency Working Group on Nanoscience. Engineering and Technology, Washington

Nisbet MC (2005) The competition for worldviews: values, information, and public support for stem cell research. Int J Public Opin Res 17(1):90-112

Nisbet MC, Lewenstein BV (2002) Biotechnology, the American media-the policy process, the elite press, 1970 to 1999. Sci Commun 23(4):359-391

Nisbet MC, Scheufele DA (2007) The future of public engagement. Scientist 21(10):39-44

Nisbet MC, Scheufele DA, Shanahan J, Moy P, Brossard D, Lewenstein BV (2002) Knowledge, reservations, or promise? A media effects model for public perceptions of science and technology. Commun Res 29(5):584-608

Nisbet MC, Brossard D, Kroepsch A (2003) Framing science: the stem cell controversy in the age of press/politics. Harv Int J Press/Polit 8(2):36-70

Olofsson A, Ohman S, Rashid S (2006) Attitudes to gene technology: the significance of trust in institutions. Eur Soc 8(4):601-624

Pew Internet and American Life Project (2006) The Internet as a resource for news and information about science. http:// www.pewinternet.org/pdfs/PIP_Exploratorium_Science. pdf. Accessed 20 Aug 2008

Pidgeon N, Harthorn BH, Bryant K, Rogers-Hayden T (2009) Deliberating the risks of nanotechnologies for energy and health applications in the United States and United Kingdom. Nat Nanotechnol 4:95-98

President's Council of Advisors on Science and Technology (PCAST) (2005) The National Nanotechnology Initiative at five years: assessment and recommendations of the National Nanotechnology Advisory Panel. http://www.nano. gov/FINAL_PCAST_NANO_REPORT.pdf. Accessed 20 Aug 2008

Priest SH (2001) Misplaced faith-communication variables as predictors of encouragement for biotechnology development. Sci Commun 23(2):97-110

Priest SH, Bonfadelli H, Rusanen M (2003) The "trust gap" hypothesis: predicting support for biotechnology across national cultures as a function of trust in actors. Risk Anal 23(4):751-766

Roco MC, Bainbridge WS (2003) Nanotechnology: societal implications-maximizing benefit for humanity. A report of the National Nanotechnology Initiative Workshop, Arlington, VA

Satterfield T, Kandlikar M, Beaudrie CEH, Conti J, Harthorn BH (2009) Anticipating the perceived risk of nanotechnologies. Nat Nanotechnol 4:752-758

Scheufele DA (1999) Framing as a theory of media effects. J Commun 49(1):103-122

Scheufele DA (2001) Democracy for some? How political talk both informs and polarizes the electorate. In: Hart RP, Shaw D (eds) Communication and U.S. elections: New Agendas. Rowman and Littlefield Publishers, Lanham, pp 19-32

Scheufele DA (2002) Examining differential gains from mass media and their implications for participatory behavior. Commun Res 29(1):46-65

Scheufele DA, Lewenstein BV (2005) The public and nanotechnology: how citizens make sense of emerging technologies. J Nanopart Res 7:659-667

Scheufele DA, Corley EA, Shih T-J, Dalrymple KE, Ho SS (2009) Religious beliefs and public attitudes toward nanotechnology in Europe and the United States. Nat Nanotechnol 4(2):91-94

Schutz H, Wiedemann PM (2008) Framing effects on risk perception of nanotechnology. Public Underst Sci 17(3): 369-379

Sententia W (2004) Neuroethical considerations: cognitive liberty and converging technologies for improving human cognition. Ann N Y Acad Sci 1013:221-228

Siegrist M (2000) The influence of trust and perceptions of risks and benefits on the acceptance of gene technology. Risk Anal 20:195-203 
Siegrist M, Cvetkovich G, Roth C (2000) Salient value similarity, social trust, and risk/benefit perception. Risk Anal 20(3): 353-362

Sinclair J, Irani T (2005) Advocacy advertising for biotechnology. J Advert 34(3):59-73

Sjoberg L (2002) Attitudes toward technology and risk: going beyond what is immediately given. Policy Sci 35(4): $379-400$

Sjoberg L (2004) Principles of risk perception applied to gene technology. EMBO Rep 5:S47-S51

Sjoberg L, Winroth E (1986) Risk, moral value of actions, and mood. Scand J Psychol 27(3):191-208

Slovic P (1987) Perception of risk. Science 36:280-285

Slovic P (1999) Trust, emotion, sex, politics and science: surveying the risk-assessment battlefield. Risk Anal 19(4): 689-701
Starr C (1969) Social benefit versus technological risk. Science 165(3899):1232-1238

Stephens LF (2005) News narratives about nano S\&T in major U.S. and non-U.S. newspapers. Sci Commun 27(2):175-199

Sturgis P, Allum N (2004) Science in society: re-evaluating the deficit model of public attitudes. Public Underst Sci 13(1): 55-74

Sturgis P, Cooper H, Fife-Schaw C (2005) Attitudes to biotechnology: estimating the opinions of a better-informed public. New Genet Soc 24(1):31-56

Sztompka P (1999) Trust: a sociological theory. Cambridge University Press, Cambridge

Vandermoere F, Blanchemanche S, Bieberstein A, Marette S, Roosen J (2010) The morality of attitudes toward nanotechnology: about God, techno-scientific progress, and interfering with nature. J Nanopart Res 12:373-381 